\title{
Biodegradable Airway Stents - Bench to Bedside: A Comprehensive Review
}

\author{
Hervé Dutau $^{\text {a }}$ Ali Imran Musani ${ }^{b}$ Sophie Laroumagne ${ }^{a} \quad K^{2}$ aid Darwiche ${ }^{c}$ \\ Lutz Freitag ${ }^{c}$ Philippe Astoula, ${ }^{a}$ \\ ${ }^{a}$ Thoracic Oncology, Pleural Diseases and Interventional Pulmonology Department, North University Hospital, \\ Marseille, France; ${ }^{\mathrm{b}}$ Interventional Pulmonology Program, Pulmonary and Critical Care Medicine, National Jewish \\ Health, Denver, Colo., USA; ' Department of Interventional Pneumology, Ruhrlandklinik, West German Lung Center, \\ University Hospital, University Duisburg-Essen, Essen, Germany; ${ }^{d}$ Aix-Marseille University, Marseille, France
}

\section{Key Words}

Airway stenting · Degradable biomaterials · Biodegradable stents $\cdot$ Animals $\cdot$ Humans

\begin{abstract}
Airway stents are indicated to treat symptomatic narrowing or to close fistulas of the central airways. They are generally divided into two types: the silicone stents and the metallic stents. Unlike in malignancies, removability is a major objective of temporary stenting in benign conditions, which poses the challenge of a new rigid bronchoscopic procedure under general anesthesia and stent removal with all its attendant risks and costs. The concept of a biodegradable (BD) stent that could maintain the patency of an airway for a predetermined duration of time is very appealing. These BD stents would gradually degrade and eventually vanish from the airway once they are no longer needed. Such stents are currently an area of intense research. Another very promising concept of drug delivery with such stents is also a very exciting area of current research. The aim of this comprehensive review is to discuss all pertinent available literature on the use of BD materials in various clinical applications and to extensively review all animal and humans trials involving $B D$ airway stents.

(c) 2015 S. Karger AG, Basel
\end{abstract}

(C) 2015 S. Karger AG, Basel

0025-7931/15/0906-0512\$39.50/0

\section{Introduction}

The main purpose of a stent in the airways is to restore and maintain patency. Any endoluminal or extrinsic pathology causing more than 50\% reduction in airway lumen and leading to debilitating symptoms such as dyspnea may be an indication for airway stents $[1,2]$. Five major indications for airway stenting include [2]: extrinsic airway compression from tumors or lymph nodes, maintenance of airway patency after debulking of intraluminal benign or malignant obstruction, treatment of benign stenoses, stabilization of collapsing airways in conditions such as malacia, and treatment of fistulas (e.g. stump dehiscences or tracheoesophageal fistulas). Airway stents are generally divided into two types: the silicone stents and the metallic stents $[2,3]$.

In malignant conditions, both silicone and metallic stents show a similar efficacy and safety profile [4-6] due to a short life expectancy despite the lack of a randomized study comparing the two kinds of stents. Patients usually expire prior to any discernable difference in terms of long-term complications related to different types of stents being detected. In addition, in malignant conditions, palliation is often the objective, and removability of the stent is generally not a concern due to the short sur-

\section{KARGER 125}

E-Mail karger@karger.com

www.karger.com/res
Dr. Hervé Dutau

Pleural Diseases and Interventional Pulmonology Department

North University Hospital, chemin des Bourrely

FR-13915 Marseille cedex 20 (France)

E-Mail hdutau@ap-hm.fr 
vival of the patient. Exceptions to the above are treatment-naïve patients with malignant central airway obstruction who underwent stenting for relief of dyspnea. Small-cell-carcinoma patients who received chemotherapy and non-small-cell-carcinoma patients who underwent radiotherapy can often demonstrate a reduction in the tumor size thus eliminating the need for long-term stenting. Treating benign lesions with airway stents requires particular attention to issues such as long-term complications and removability [2]. In general, only removable stents should be used for these indications until a multidisciplinary team has considered and exhausted $[2,3,7]$ all other options including surgical repair. Even though airway stenting is generally considered as a palliative treatment, some studies suggest that it can be curative in and of itself. Benign posttracheostomy or postintubation tracheal stenosis can be successfully treated with silicone stents if held in place for 18 months in about $70 \%$ of the cases [8]. Similarly, anastomotic strictures after lung transplantation can also be treated with silicone stents with the same percentage of success when the stent is placed for a duration of 9 months [9]. Thus removability is a major objective of temporary stenting in benign disease, which poses the challenge of a new rigid bronchoscopic procedure under general anesthesia and stent removal with all its attendant risks and costs. The concept of a biodegradable (BD) stent that could maintain the patency of an airway for a predetermined duration of time is very appealing. These BD stents would gradually degrade and eventually vanish from the airway once they are no longer needed. Such stents are currently an area of intense research. Another very promising concept of drug delivery with such stents is also a very exciting area of current research.

The aim of this comprehensive review is to discuss all pertinent available literature on $\mathrm{BD}$ materials and their use in various clinical applications. We will also extensively review all animal and humans trials involving BD airway stents in this review article.

\section{Existing BD Materials}

Degradable materials must fulfill more stringent criteria in terms of their biocompatibility than nondegradable materials. In addition to the potential problem of toxic contaminants leaching from the implant, one must also consider the potential toxicity caused by the degradation products and subsequent metabolites [10]. Over the last decade, a number of hydrolytically unstable polymers have been suggested as degradable biomaterials. However, in most cases, no attempts have been made to develop

Biodegradable Airway Stents - Bench to Bedside these new materials for specific medical applications. In addition, only a small fraction of these polymers have been studied in terms of their in vivo toxicological profiles, degradation rates and mechanisms, and their physicomechanical properties [10]. An even smaller number of synthetic, degradable polymers have been used in medical implants and devices that have gained approval by the United States Food and Drug Administration (FDA) for use in patients. The FDA does not approve polymers or materials per se, but only specific medical devices and drug delivery formulations. As of 2006, only seven distinct synthetic, degradable polymer classes have been approved for use in a narrow range of clinical applications [11]. These polymers are polyesters containing lactic acid (poly-L-lactic acid, PLLA), polyesters containing glycolic acid (poly-L-glycolic acid, PLGA), polyesters containing dioxanone (polydioxanone, PDS), polyesters containing caprolactone (polycaprolactone, PCL), poly(trimethylene carbonates), polyanhydrides containing sebacic acid, and tyrosine-derived polyarylates. Various other synthetic, degradable biomaterials currently in clinical use are blends or copolymers of these base materials such as a wide range of copolymers of lactic and glycolic acid.

\section{Mechanisms of Degradation and in vitro Testing of Biomaterials Used for Stents}

The term 'degradation' refers to a chemical process resulting in the cleavage of covalent bonds. Hydrolysis is the most common chemical process by which polymers degrade but degradation can also occur via oxidative, photodegradative, and enzymatic mechanisms [10]. All polymers undergo some degree of degradation. Göpferich [12] defined 'degradable polymers' as those that degrade within the time scales of their expected service life or shortly thereafter. Conversely, 'nondegradable' polymers have degradation times that are substantially longer than their service life. Currently, at least four different terms (biodegradation, bioerosion, bioabsorption, and bioresorption) are used to indicate that a given material or device will eventually disappear after having been introduced into a living organism. The terms 'bioresorption' and 'bioabsorption' are used interchangeably and often imply that the polymer or its degradation products are removed by cellular activity (e.g., phagocytosis) in a biological environment.

Fibers made of PLLA, PDS, and polyglycolide-co- $\varepsilon$ caprolactone (PGACL) combine a relatively high initial strength and modulus together with sufficient ductility 
and flexibility, and are therefore often chosen for use in stents [13]. In vitro, the effect of degradation on the tensile mechanical properties and morphology of these fibers has been examined. The expandable stents developed from these fibers demonstrate excellent initial radial compression strength. The PLLA stents exhibited excellent in vitro degradation resistance and can therefore support body conduits such as blood vessels for prolonged periods of time. PDS and PGACL stents can afford good support for 5 and 2 weeks, respectively, and can therefore be utilized for short-term applications. The degradation resistance of the stents correlates with the profile of mechanical property deterioration of the corresponding bioresorbable fibers.

\section{Research and Medical Applications of Degradable Biomaterials}

Five main kinds of degradable implants are possible:

1 A temporary support device is used when the natural tissue bed has been weakened by a disease, injury or as a result of surgery and requires some artificial support. The degradable implant would provide temporary, mechanical support until the natural tissue heals and regains its strength. In order for a temporary support device to work properly, a gradual stress transfer should occur: as the natural tissue heals, the degradable implant should gradually weaken. The need to adjust the degradation rate of the temporary support device to the healing of the surrounding tissue represents one of the major challenges in the design of such devices. Sutures for a healing wound or fixation devices for a broken bone [14] would be examples of the corresponding support devices. Tubular degradable stents have been manufactured for the treatment including various vascular (mainly coronary diseases) [15-23] and esophageal or bile duct [24-28] conditions as well as urethral $[29,30]$ strictures and have already been tested in animals and humans.

2 A temporary barrier has its major medical use in the prevention of postsurgical adhesions. During surgical closure, barrier devices are interposed between tissues that must remain separate following surgery.

3 Implantable drug delivery devices and injectable polymer-drug-depot delivery systems are capable of delivering drugs to specific locations over an extended period of time. They are, by necessity, temporary devices, for the drug reservoir will eventually be depleted or the need for delivery of a specific drug will be eliminated once the disease has been adequately treated. The development of implantable drug delivery systems is probably the most widely investigated application of degradable polymers [31].

4 The tissue-engineering scaffold is a degradable implant that is designed to act as an artificial extracellular matrix by providing space for cells to grow into and be reorganized into functional tissue [32-34].

5 Multifunctional devices combine several of the abovementioned functions within a single device [35-37]. Vascular and coronary stents are designed to mechanically prevent the collapse and restenosis of arteries that have been opened by balloon angioplasty and can deliver drugs (anti-inflammatory or anti-thrombogenic agent) directly to the site of vascular injury [3841]. Drug-eluting/BD stents have also been studied in gastrointestinal diseases [42]. In vitro and animal studies have been conducted as well with $\mathrm{BD}$ tracheal stents either coated with dexamethasone [43, 44], cisplatin [45], or with mitomycin C (MMC) [46]. Zilberman et al. $[43,44]$ incorporated dexamethasone in a PLLA stent and showed that the cumulative release of dexamethasone from the stents was linear. Drug incorporation had a minor effect on the initial stent strength. Chao et al. [45] studied a degradable stent made of PCL coated with polylactide-polyglycolide copolymer and cisplatin. Kong et al. [47] studied, in vitro, the PLGA tracheal stent loaded with paclitaxel and demonstrated a favorable surface morphology as well as sustained and effective drug release behavior.

\section{Airway Stenting with Degradable Biomaterials}

Extraluminal splinting or scaffolding of the central airway with $\mathrm{BD}$ materials has also been studied in animals [48-57] and in two case reports in humans $[58,59]$. The main objectives of these procedures were to stabilize a collapsing airway or to assist airway healing or remodeling after tracheal injury or surgery. Biomaterials used were diverse: copolymers of PLLA and PLGA [48-50], a copolymer derived from a dextran sulfate gelatin [51], a 3-layer scaffold consisting of a collagen sheet, a PLGA mesh, and a copolymer (L-lactide/ $\varepsilon$-caprolactone) coarse mesh [52], a copolymer of L-lactide and $\varepsilon$-caprolactone sponge tube reinforced by PLGA $[53,54]$, a polypropylene mesh tube with reinforcing rings with collagen extracted from porcine skin was conjugated to this frame and the luminal surface coated with a polymer, poly(L-lactic acid-co- $\varepsilon$ caprolactone) [55], a 3-dimensionally printed, bioresorb- 
Table 1. Animal studies

\begin{tabular}{|c|c|c|c|c|c|}
\hline Chao [45], 2013 & Rabbits (15) & $\begin{array}{l}\text { PCL coated with } \\
\text { PLLA-PLGA }\end{array}$ & $\begin{array}{l}\text { Mesh-type stent made of } \\
\text { interconnected ring-ellipse-ring units }\end{array}$ & Surgery & NS \\
\hline Novotny [67], 2012 & Rabbits (25) & PDS & Tubular and hollowed braided stent & $\begin{array}{l}\text { Endoscopy + } \\
\text { fluoroscopic guidance }\end{array}$ & 2.5 months \\
\hline Saito [65], 2004 & Dogs (6) & PLLA & Knitted and hollowed tubular stent & Endoscopy & NS \\
\hline Saito [64], 2002 & Rabbits (15) & PLLA & Knitted and hollowed tubular stent & Surgery & 14 months \\
\hline Robey [63], 2000 & Rabbits (25) & PLGA & Helical stent & Surgery & 3.5 months \\
\hline Korpela [61], 1999 & Rabbits (11) & PLLA & Helical stent & Surgery & NS \\
\hline Korpela [62], 1998 & Rabbits (9) & PLLA & Helical stent & Surgery & NS \\
\hline
\end{tabular}

able airway splint made of PCL $[56,59]$, and an external stent made of magnesium-yttrium alloy [57].

\section{Animal Studies}

Ten animal studies [45, 46, 60-67] regarding BD endoluminal airway stents have been published (table 1). The first study was performed in 35 rats by Lochbihler et al. [60] using stents made of vicryl filaments, surgically implanted in the trachea through a cervical median incision. Absorption time and compatibility were investigated. After 2 months no stent residues could be detected, whereas only signs of mild, chronic fibrotic inflammation persisted. No evidence for aspirations of foreign bodies or progressive inflammatory changes of the mediastinum was found.

Korpela et al. [61] experimented with self-reinforced PLLA helical stents in 18 rabbits and compared the local tracheal mucosal reaction to silicone stents; both stents were surgically implanted. PLLA stents were very well tolerated and caused only minor tissue reactions. Scanning electron-microscopic studies showed the ciliated cell layer was well spared between the spirals of the stent. The same authors [62] conducted another experiment in 32 rabbits and compared three types of stents (PLLA, silicone, and uncovered metallic stents). Their conclusions were that silicone stents had a tendency to occlude while stents made of metal and of self-reinforced PLLA were well tolerated.

Robey et al. [63] studied in vitro, mechanical and degradative properties of PLGA helical stents. Significant mass loss was noted in vitro until after 5 weeks in buffer solution. By 14 weeks, the stents were nearly 100\% degraded. The stents were then studied in vivo in a group of rabbits (12 were stented and 13 served as controls) who underwent anterior patch tracheoplasties. The stridor rate for the control group was higher than the stented group (38 vs. $17 \%$ ) and a significantly higher average stenosis (34 vs. 23\%) across the entire reconstruction site.

Saito et al. [64] surgically inserted PLLA stents in 15 rabbits and silicone stents in 8 rabbits. Biocompatibility and mechanical strength were studied. Good biocompatibility of PLLA stents was noted. The mechanical strength of silicone stents was greater than that of PLLA stents. The mechanical strength of PLLA stents increased as a function of their diameter. Degradation time was estimated at 14 months.

The first experimental study using endoscopic placement of degradable stents was conducted by Saito et al. [65] in 6 dogs. The objective was to assess the placement feasibility of a knitted tubular PLLA stent. The delivery system consisted of a flexible balloon catheter preloaded with a stent which was advanced to a target point in the trachea under bronchoscopic guidance. Once the stent was positioned, the balloon was inflated for $60 \mathrm{~s}$. All stents were successfully placed with full contact with the tracheal wall.

PCL-made stents were for the first time studied in 6 rabbits by Liu et al. [66]. Safety and biocompatibility were investigated and were found to be good by the authors. Degradation time was estimated to be more than 33 
months. PCL could be a promising bioresorbable material for stent design if prolonged degradation time is required.

Zhu et al. [46] investigated the effects and efficacy of a novel bioabsorbable tracheal stent made of a copolymer of PLLA and PCL with different designs (helical or tubular) in the rabbit model. They tested it with and without MMC elution for the prevention of diathermic-induced tracheal stenosis and compared it to silicone stents. All stents were surgically implanted. Tubular stents + MMC performed best. Tracheal stenosis was most significant for the helical stents, the control group, the group with tubular stents, and then the group with silicone stents. After 12 weeks, tracheal stenosis for the tubular stents + MMC was only half that of the silicone stents.

The first animal study using PDS as bioresorbable material was conducted by Novotny et al. [67] in rabbits. Stents were implanted bronchoscopically and under fluoroscopic guidance. The objectives were to study the biocompatibility of the stents using histological examinations and the degradation time. This latter was 10 weeks and the authors found an acceptable safety and biocompatibility.

Finally, Chao et al. [45] investigated the in vitro mechanical strength of a new cisplatin-eluting bioabsorbable stent made of PLLA-PLGA copolymer. Subsequently, the stents were surgically implanted in tracheas of the rabbits to study the in vivo cisplatin release. In vitro, mechanical strength was found comparable to the strength of a selfexpandable metallic stent, and steady release of cisplatin for 4 weeks was observed. The in vivo study showed sustained cisplatin levels in rabbit trachea for 5 weeks. Degradation time of the stents was not calculated.

\section{Human Studies}

The literature regarding airway BD stents in humans is scarce. Lischke et al. [68] conducted a pilot study in order to evaluate the safety and efficacy of BD stents made of PDS (Ella-Cs, Ltd., Hradec Králové, Czech Republic) (fig. 1) to treat bronchial anastomotic stenosis in patients after lung transplantation. Twenty stents were implanted endoscopically in 6 patients presenting with posttransplant bronchial anastomotic stenoses (fig. 2). The endoscopic procedures included balloon dilation of the bronchial narrowing followed by the placement of the PDS self-expandable stent. The median stent diameter was 12 $\mathrm{mm}(8-17 \mathrm{~mm})$ and median length was $20 \mathrm{~mm}(12-30$ $\mathrm{mm}$ ). All patients were evaluated clinically by bronchoscopy and high-definition computed tomography. All stents were placed successfully and relieved the steno-

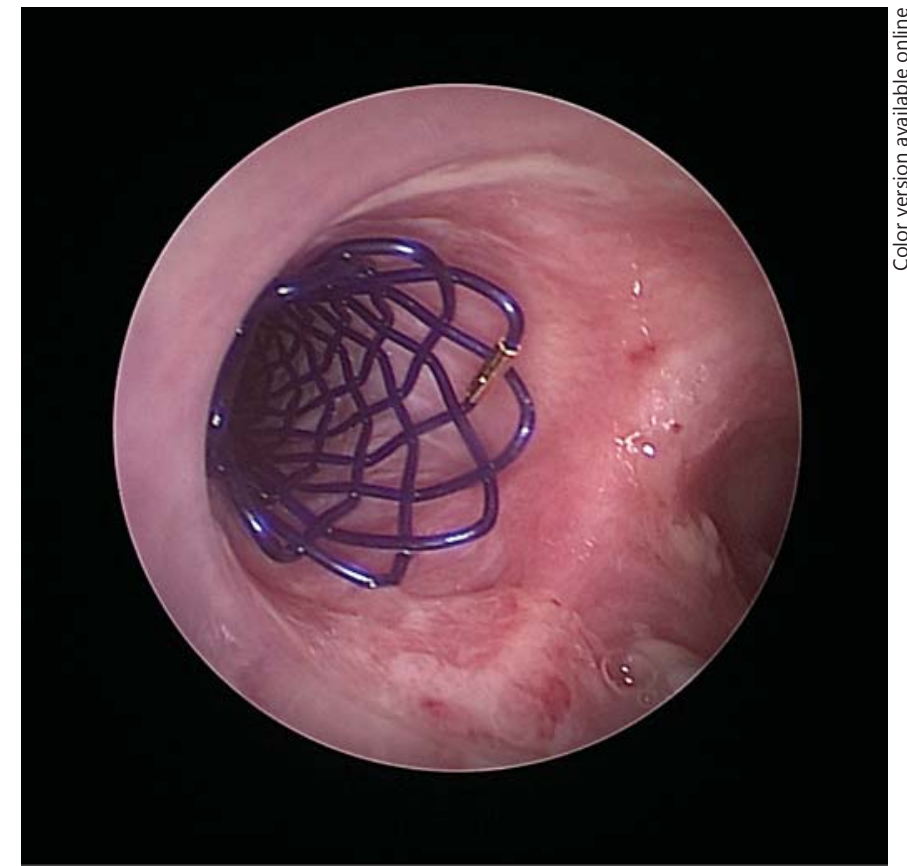

Fig. 1. PDS stent placed in the left main stem bronchus stenosis.

sis in all cases. No complication was noted during stent placement. Four patients needed multiple stenting for anastomotic restenosis. Median time to any restenting was 5 months (2-15 months). One patient died from a pulmonary embolus and the remaining 5 were found to be in good clinical condition for up to 4 years (median 40 months, range 7-48 months) since first stenting and intervention free for up to 44 months (median 24 months, range 7-44 months).

Vondrys et al. [69] reported their experience with BD PDS stents for tracheal narrowing in children. Eleven custom-made PDS stents were implanted in 4 patients with airway narrowing due to external compression or intrinsic collapse. The median stent diameter was $9 \mathrm{~mm}(6-14$ $\mathrm{mm}$ ) and the median length was $15 \mathrm{~mm}(13-70 \mathrm{~mm})$. Narrowing was initially relieved in all cases. There was no bleeding or perforation after stent implantation. Size mismatching was a problem in 2 cases. Three patients needed repeated stenting after stent absorption. There was 1 death, unrelated to the stent implantation. All 3 survivors were found to be in good clinical condition for up to 12 months after first stenting.

In a retrospective study, Serio et al. [70] described their experience of airway stenting in the management of tracheobronchial obstruction in children. During a period of 7 years, 235 stents were placed in 100 children. One 
Fig. 2. Endoscopic view after stent insertion $(\mathbf{a}, \mathbf{c})$ and after stent degradation $(\mathbf{b}, \mathbf{d})$ (courtesy of Dr. Jens Gottlieb, Hannover, Germany).
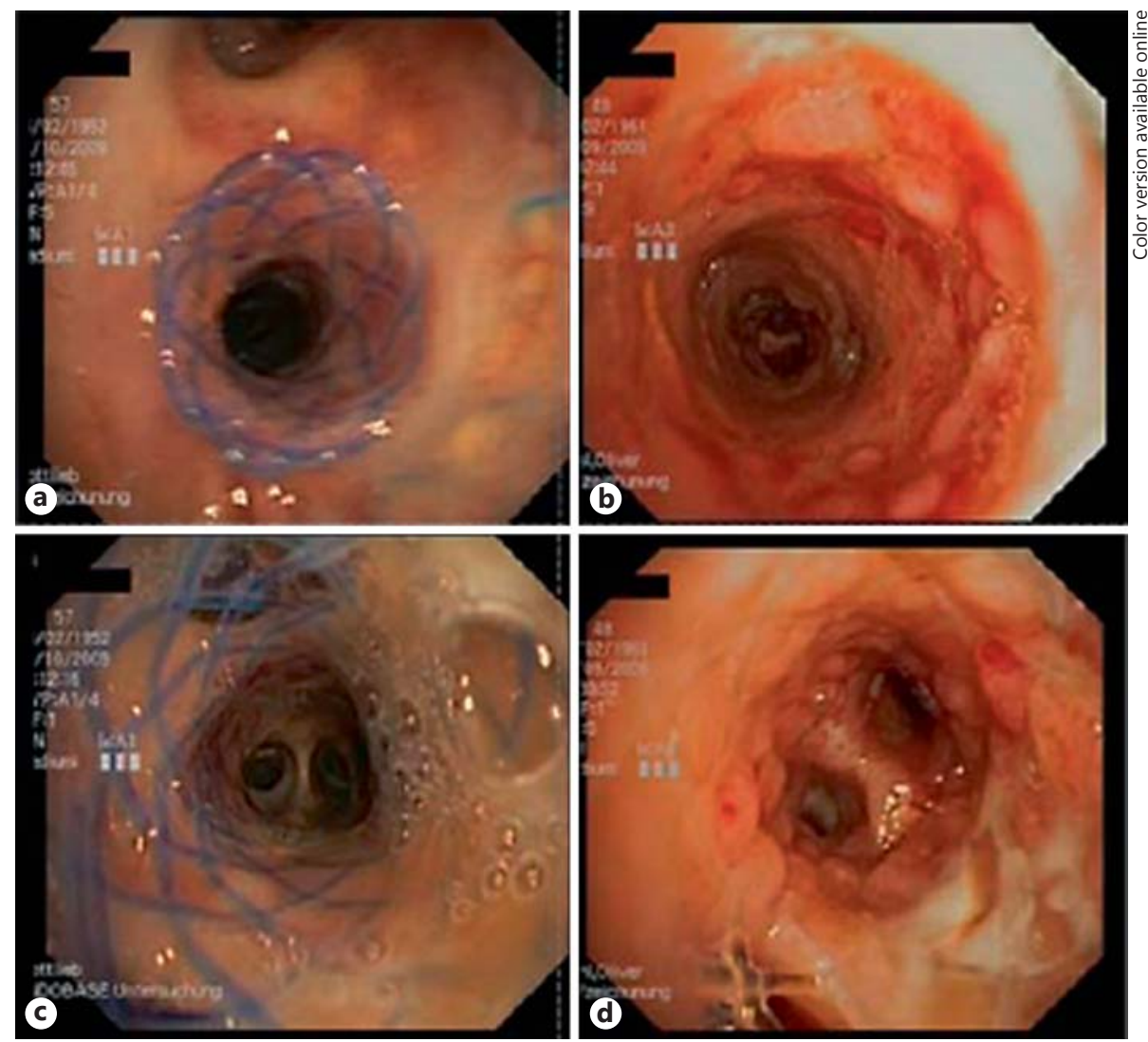

hundred and twelve stents were made of silicone, 120 were metallic and 3 were $\mathrm{BD}$ (PDS). The $\mathrm{BD}$ stents were implanted in 3 different patients. In the first case of a 2 -year-old girl, the stent was placed to treat a posttracheostomy tracheal stenosis after failure of one silicone and one metallic stent (excessive granulation tissue in both cases). The radial force of the degradable stent was not sufficient enough to maintain the patency of the tracheal lumen and was subsequently removed. A tracheostomy was required. In the second case of a 6-month-old boy, a degradable stent was placed to manage a malacia of the left main stem bronchus. After 4 months, the stent was completely degraded and the malacia recurred and required placement of a metallic stent. In the third case, a preterm baby was treated for a tracheal stenosis with a degradable stent after the failure of a silicone and then a metallic stent. It was removed after 10 days because it was not effective and a silicone Y stent was placed.

In a retrospective study focusing on the management of severe complications following slide tracheoplasty as the treatment of congenital tracheal stenosis in 14 patients, Antón-Pacheco et al. [71] described the endoscop-

Biodegradable Airway Stents - Bench to Bedside ic management of one case of postoperative tracheal stenosis with a PDS BD stent. After repeated endoscopic balloon dilatations that did not yield satisfactory results, a custom-made self-expanding PDS stent ( $5 \mathrm{~mm}$ diameter $\times 15 \mathrm{~mm}$ length; Ella-Cs, Ltd.) was inserted in the distal trachea 3 months after slide tracheoplasty. It was well tolerated, with mild granulation tissue formation, but maintained the tracheal patency. Thus, repeated stenting after stent absorption was necessary 3 times with increased diameter stents $(6-8 \mathrm{~mm})$ in order to provide full internal support to the entire trachea. Follow-up bronchoscopies were necessary to dilate the stents and remove soft granulation tissue. The tolerance of the stent was deemed satisfactory with the patient remaining in good clinical condition 1 year after the first stent placement.

\section{Discussion}

Metallic and silicone stent-related complications (granulation tissue, mucous plugging, microbial colonization, and fracture) are the main challenges for both pa- 
Table 2. Human studies

\begin{tabular}{llll}
\hline First author [Ref.], year & BD material & Patients/stents & Indications \\
\hline Lischke [68], 2011 & PDS & 6 adults/20 stents & Anastomotic stenosis after lung transplantation \\
\hline Vondrys [69], 2011 & PDS & 4 children/11 stents & External compression or intrinsic collapse \\
\hline Serio [70], 2014 & PDS & 3 children/3 stents & $\begin{array}{l}\text { (1) Tracheal stenosis after tracheostomy } \\
\text { (2) Left main stem bronchus malacia } \\
\text { (3) Tracheal stenosis }\end{array}$ \\
\hline Antón-Pacheco [71], 2014 & PDS & & Postoperative tracheal stenosis \\
\hline
\end{tabular}

tients and physicians when these devices are left in place for a long period of time [2]. These situations are almost exclusively encountered in cases of benign conditions when complications have time to occur, unlike in malignancies, where the majority of patients have limited survival. In the case of benign and symptomatic central airway narrowing, metallic stents that are not fully covered should be excluded from the physician's list of options because their removal can be very difficult and expose the patients to severe potential complications $[2,7]$. Silicone and fully covered stents are the only acceptable options due to their relatively easy removability [3]. Previous studies have shown that after stent removal, conditions such as postintubation or posttracheostomy tracheal stenosis [8] and postlung transplantation anastomotic bronchial strictures [9] can be stabilized for a prolonged period of time in about $70 \%$ of the cases. In these studies, silicone stents were left in place for a mean duration of 9-18 months. These time periods suggest a potential benchmark for the longevity of the BD stents.

Animal studies show that the degradation time for the degradable biomaterial can vary from 8 weeks (Vicryl) to 14 months (PLLA). PDS and PLGA have a shorter degradation time (10 and 14 weeks, respectively) while PCL seems to have a significantly longer degradation time ( $>33$ weeks). The time of absorption of a degradable stent can be modified depending on the choice of the basic molecule with which it is manufactured, the shape, the degree of polymerization, the internal arrangement of the material components, and the site of implantation [60]. Saito et al. $[64,65]$ reported that PLLA stents begin to degrade in 5-6 months while the total degradation time of PLLA is more than 1 year. Degradation time can be changed if the properties of the polymer such as the molecular weight, the size of the wire, and the shape are modified. The total degradation time of PLLA wire used in their study is predicted as 14 months, which is close to the mean duration to treat benign tracheal stenosis in humans.

Only 4 papers report the use of BD stents in humans (table 2). The total number of patients in these papers is only 14 , and the number of stents placed is 35 .

In the pediatric literature, there are only 3 papers on this subject. In all the cases, stents where made of PDS. Endoscopic placement of these self-expandable stents seemed safe and user friendly in pediatric patients but failed to maintain airway patency in 2 patients [69] requiring their immediate removal. In the 12 remaining patients, the stents relieved the airway narrowing in the short-term but recurrences occurred in all the cases after stent degradation after 4-5 months of initial stenting. Of the 12 patients, 11 patients needed repeated $\mathrm{BD}$ stent placements and 1 was treated with a metallic stent.

In general, based on the data discussed earlier, degradation times seem longer in humans ( $4-5$ months) compared to animals (2.5 months) [66].

There is no comparative study but it seems that the radial force of the Ella stent is lower than for self-expandable metallic or silicone stents. Only uncovered stents are available so they are not convenient for malignant conditions or fistulas. Their costs are higher than for other stents (above EUR 1,000).

At this time, neither PLLA, which seems promising in terms of degradation time, nor the combination of a BD and active stent has been attempted in humans. This seems surprising in comparison with other medical specialties such as cardiology in which stents made of different BD materials have been successfully tested in coronary artery diseases. In a recent review [23] the majority of the published studies have tested PLLA or PLGA BD stents activated with anti-proliferative agents and nonpolymeric $\mathrm{BD}$ stents such as stents made of magnesium [28]. BD stents have been largely investigated in humans for the treatment of diverse gastrointestinal diseases. The 
vast majority of these stents used PDS as the BD material [28]. PDX stents seem to be an attractive alternative to repeated dilations or surgery in patients with benign stenoses of the esophagus and of the small and large intestines. PDX stents have shown promising results but some aspects of this material/these stents need further improvement such as the loss of radial force over time due to the degradable material, which can induce mucosal or parenchymal injuries [28]. These issues in addition to a modest clinical efficacy have allowed limited indications of BD stents in gastroenterology [28].

In conclusion, benign, symptomatic, central airway diseases may require stents that must serve a temporary rather than a permanent purpose. Additionally, the use of $\mathrm{BD}$ stents could circumvent the long-term complications of permanent stents. However, BD implants are not without safety concerns, such as the toxicity of their degradation products and the degradation-related, premature failure of the implant. A large proportion of the currently investigated synthetic and degradable polymers are polyesters. It remains to be seen whether some of the alternative backbone structures such as polyanhydrides, polyphosphazenes, polyphosphonates, polyphosphoesters, polyamides [72], polycarbonates or magnesium will be able to compete with the well-established and well-stud- ied position of the polyesters in the future. Manufacturers of BD stents will have to proceed to mechanical and physical research to adapt the design, the degradation time and the mechanical properties of their devices in order to withstand various environments such as airways. Stent size, shape, and mass are probably equally important for their biomechanical and degradation behavior. Hypothetically, a stent designed like a full tube of $\mathrm{BD}$ material will probably have a longer degradation time than a hollowed stent made with the same BD material. Ideal indications for BD stents in human airways have yet to be defined. Prospective studies are desperately needed in this area to answer the fundamental questions mentioned above and to determine whether there is a potential role of these stents in the rapidly widening horizon of the therapeutic bronchoscopies. With the advent of $\mathrm{BD}$, active, and 3-dimensionally printed stents, the science of airway stenting has entered into a very promising phase of evolution. This evolution is particularly relevant in the era of personalized medicine.

\section{Financial Disclosure and Conflicts of Interest}

The authors have no conflicts of interest to reveal.

\section{References}

1 Wood DE, Liu YH, Vallieres E, et al: Airway stenting for malignant and benign tracheobronchial stenosis. Ann Thorac Surg 2003;76: 167-174.

2 Freitag L: Airway stents; in Strausz J, Bolliger CT (eds): Interventional Pulmonology. Eur Respir Mon 2010;18:190-217.

-3 Dutau H, Musani AI, Plojoux J, Laroumagne S, Astoul P: The use of self-expandable metallic stents in the airways in the adult population. Expert Rev Respir Med 2014;8:179-190.

4 Dutau H, Toublanc B, Lamb C, et al: Use of the Dumon Y-stent in the management of malignant diseases involving the carina: a retrospective review of 86 patients. Chest 2004; 126:951-958.

-5 Breitenbucher A, Chhajed PN, Brutsche MH, et al: Long-term follow-up and survival after Ultraflex stent insertion in the management of complex malignant airway stenoses. Respiration 2008;75:443-449.

6 Saji H, Furukawa K, Tsutsui H, et al: Outcomes of airway stenting for advanced lung cancer with central airway obstruction. Interact Cardiovasc Thorac Surg 2010;11:425-428.

7 FDA - US Food and Drug Administration: FDA Public Health Notification: complica- tions from metallic tracheal stents in patients with benign airway disorders. July 29, 2005. www.fda.gov/MedicalDevices/Safety/AlertsandNotices/PublicHealthNotifications/ UCM062115

-8 Galluccio G, Lucantoni G, Battistoni P, et al: Interventional endoscopy in the management of benign tracheal stenoses: definitive treatment at long-term follow-up. Eur J Cardiothorac Surg 2009;35:429-433.

-9 Dutau H, Cavailles A, Sakr L, Badier M, Gaubert JY, Boniface S, Doddoli C, Thomas $\mathrm{P}$, Reynaud-Gaubert M: A retrospective study of silicone stent placement for management of anastomotic airway complications in lung transplant recipients: short- and long-term outcomes. J Heart Lung Transplant 2010;29: 658-664.

10 Treiser M, Abramson S, Langer R, Kohn J: Degradable and resorbable biomaterials; in Ratner BD, Hoffman AS, Schoen FJ, Lemons JE (eds): Biomaterials Science: An Introduction to Materials in Medicine, ed 3. New York, Elsevier, 2013, pp 179-195.

11 Kohn J, Welsh WJ, Knight D: A new approach to the rationale discovery of polymeric biomaterials. Biomaterials 2007;28:4171-4177.
12 Göpferich A: Mechanisms of polymer degradation and erosion. Biomaterials 1996;17: 103-114.

13 Zilberman M, Nelson KD, Eberhart RC: Mechanical properties and in vitro degradation of bioresorbable fibers and expandable fiberbased stents. J Biomed Mater Res B Appl Biomater 2005;74:792-799.

14 Rokkanen P, Böstman O, Vainionpää S, et al: Biodegradable implants in fracture fixation: early results of treatment of fractures of the ankle. Lancet 1985;1:1422-1424.

15 Labinaz M, Zidar JP, Stack RS, Phillips HR: Biodegradable stents: the future of interventional cardiology? J Interv Cardiol 1995;8: 395-405.

16 Waksman R: Biodegradable stents: they do their job and disappear. J Invasive Cardiol 2006; 18:70-74.

17 Bunger CM, Grabow N, Sternberg K, et al: A biodegradable stent based on poly(L-lactide) and poly(4-hydroxybutyrate) for peripheral vascular application: preliminary experience in the pig. J Endovasc Ther 2007;14:725-733.

18 Ramcharitar S, Serruys PW: Fully biodegradable coronary stents: progress to date. Am J Cardiovasc Drugs 2008;8:305-314.
Biodegradable Airway Stents - Bench to Bedside
Respiration 2015;90:512-521 DOI: $10.1159 / 000442054$ 
19 Ramcharitar S, Serruys PW: Biodegradable stents. Minerva Cardioangiol 2008;56:205213.

20 Garg S, Serruys P: Biodegradable stents and non-biodegradable stents. Minerva Cardioangiol 2009;57:537-565.

21 Depukat R, Rzeszutko L, Dudek D: Regeneration of vessel wall functionality and vascular restoration therapy with biodegradable stents - current status. Curr Pharm Biotechnol 2012;13:2440-2448.

-22 Gonzalo N, Macaya C: Absorbable stent: focus on clinical applications and benefits. Vasc Health Risk Manag 2012;8:125-132.

23 Sammel AM, Chen D, Jepson N: New generation coronary stent technology - is the future biodegradable? Heart Lung Circ 2013;22: 495-506.

$\checkmark 24$ Fry SW, Fleischer DE: Management of a refractory benign esophageal stricture with a new biodegradable stent. Gastrointest Endosc 1997;45:179-182.

-25 Dhar A, Topping J, Johns E, O’Neill D: Biodegradable stents in refractory benign oesophageal strictures - first report of 4 patients from UK. Gastrointest Endosc 2009;69:254-255.

26 Petrtyl J, Bruha R, Horak L, et al: Management of benign intrahepatic bile duct strictures: initial experience with polydioxanone biodegradable stents. Endoscopy 2010;42(suppl 2):E89-E90.

27 Petrtyl J, Bruha L, Horak L, Zadorova Z, Dosedel Z, Laasch HU: Polydioxanone biodegradable stents in intrahepatic bile duct stricture. Endoscopy 2010;42:89-90.

-28 Lorenzo-Zúñiga V, Moreno-de-Vega V, Marín I, Boix J: Biodegradable stents in gastrointestinal endoscopy. World J Gastroenterol 2014;20:2212-2217.

$\checkmark 29$ Kemppainen E, Talja M, Riihelä M, et al: A biosorbable urethral stent. Urol Res 1993;21: 235-238.

30 Talja M, Tammela T, Petas A, et al: Biodegradable selfreinforced polyglycolic acid spiral stent in prevention of postoperative urinary retention after visual laser ablation of the prostate-laser prostatectomy. J Urol 1995; 154:2089-2092.

-31 Nair LS, Laurencin CT: Biodegradable polymers as biomaterials. Prog Polym Sci 2007;32: 762-798.

-32 Costopoulos C, Naganuma T, Latib A, Colombo A: Looking into the future with bioresorbable vascular scaffolds. Expert Rev Cardiovasc Ther 2013;11:1407-1416.

>33 Hassell ME, Grundeken MJ, Delewi R, Wykrzykowska JJ, Piek JJ: Bioresorbable scaffolds: talking about a new interventional revolution. Minerva Cardioangiol 2013;61:165179.

>34 Hutmacher DW: Scaffold design and fabrication technologies for engineering tissues: state of the art and future perspectives. J Biomater Sci Polym Ed 2001;12:107-124.

-35 Zilberman M, Eberhart RC: Drug-eluting bioresorbable stents for various applications. Annu Rev Biomed Eng 2006;8:153-180.
6 Wykrzykowska JJ, Onuma Y, Serruys PW: Advances in stent drug delivery: the future is in bioabsorbable stents. Expert Opin Drug Deliv 2009;6:113-126.

37 Liu SJ, Chiang FJ, Hsiao CY, Kau YC, Liu KS: Fabrication of balloon-expandable self-lock drug-eluting polycaprolactone stents using micro-injection molding and spray coating techniques. Ann Biomed Eng 2010;38:31853194.

>38 Lam MK, Sen H, Tandjung K, van Houwelingen KG, et al: Comparison of 3 biodegradable polymer and durable polymer-based drugeluting stents in all-comers (BIO-RESORT): rationale and study design of the randomized TWENTE III multicenter trial. Am Heart J 2014;167:445-451.

-39 Corti R: Long-term patient benefit with biodegradable polymer biolimus eluting stent. Minerva Cardioangiol 2012;60:629-636.

40 Ahmed TA, Bergheanu SC, Stijnen T, Plevier JW, Quax PH, Jukema JW: Clinical performance of drug-eluting stents with biodegradable polymeric coating: a meta-analysis and systematic review. EuroIntervention 2011;7: 505-516.

41 Tsuji T, Tamai H, Igaki K, et al: Biodegradable stents as a platform to drug loading. Int J Cardiovasc Intervent 2003;5:13-16.

42 ASGE Technology Committee; Tokar JL, Banerjee S, Barth BA, et al: Drug-eluting/biodegradable stents. Gastrointest Endosc 2011;74: 954-958.

43 Zilberman M, Schwade ND, Meidell RS, Eberhart RC: Structured drug-loaded bioresorbable films for support structures. J Biomater Sci Polym Ed 2001;12:875-892.

44 Zilberman M, Eberhart RC, Schwade ND: In vitro study of drug-loaded bioresorbable films and support structures. J Biomater Sci Polym Ed 2002;13:1221-1240.

45 Chao YK, Liu KS, Wang YC, Huang YL, Liu SJ: Biodegradable cisplatin-eluting tracheal stent for malignant airway obstruction: in vivo and in vitro studies. Chest 2013;144:193199.

46 Zhu GH, Ng AH, Venkatraman SS, Boey FY, Wee AL, Trasti SL, Yee Lim LH: A novel bioabsorbable drug-eluting tracheal stent. Laryngoscope 2011;121:2234-2239.

-47 Kong Y, Zhang J, Wang T, Qiu X, Wang Y: Preparation and characterization of paclitaxel-loaded poly lactic acid-co-glycolic acid coating tracheal stent. Chin Med J 2014;127: 2236-2240.

48 Robey TC, Eiselt PM, Murphy HS, Mooney DJ, Weatherly RA: Biodegradable external tracheal stents and their use in a rabbit tracheal reconstruction model. Laryngoscope 2000;110:1936-1942.

49 Nalwa SS, Hartig GK, Warner T, Connor NP, Thielman MJ: Evaluation of poly-L-lactic acid and polyglycolic acid resorbable stents for repair of tracheomalacia in a porcine model. Ann Otol Rhinol Laryngol 2001;110:993-999.

50 Sewall GK, Warner T, Connor NP, Hartig GK: Comparison of resorbable poly-L-lactic acid-polyglycolic acid and internal Palmaz stents for the surgical correction of severe tracheomalacia. Ann Otol Rhinol Laryngol 2003; 112:515-521.

51 Klin B, Weinberg M, Vinograd I, Sandbank J, Siman-Tov Y, Astachov L, Ayalon O, Rochkind S, Shahar A, Nevo Z: Experimental repair of tracheal defects using a new biodegradable membrane. J Laparoendosc Adv Surg Tech A 2007;17:342-349.

52 Komura M, Komura H, Kanamori Y, Tanaka Y, Suzuki K, Sugiyama M, Nakahara S, Kawashima $\mathrm{H}$, Hatanaka A, Hoshi K, Ikada Y, Tabata Y, Iwanaka T: An animal model study for tissue-engineered trachea fabricated from a biodegradable scaffold using chondrocytes to augment repair of tracheal stenosis. J Pediatr Surg 2008;43:2141-2146.

53 Tsukada H, Matsuda S, Inoue H, Ikada Y, Osada H: Comparison of bioabsorbable materials for use in artificial tracheal grafts. Interact Cardiovasc Thorac Surg 2009;8:225229.

54 Tsukada H, Gangadharan S, Garland R, Herth F, DeCamp M, Ernst A: Tracheal replacement with a bioabsorbable scaffold in sheep. Ann Thorac Surg 2010;90:1793-1797.

55 Sato T, Araki M, Nakajima N, Omori K, Nakamura T: Biodegradable polymer coating promotes the epithelization of tissue-engineered airway prostheses. J Thorac Cardiovasc Surg 2011;141:463-468.

-56 Zopf DA, Flanagan CL, Wheeler M, Hollister SJ, Green GE: Treatment of severe porcine tracheomalacia with a 3-dimensionally printed, bioresorbable, external airway splint. JAMA Otolaryngol Head Neck Surg 2014; 140:66-71.

57 Luffy SA, Chou DT, Waterman J, Wearden PD, Kumta PN, Gilbert TW: Evaluation of magnesium-yttrium alloy as an extraluminal tracheal stent. J Biomed Mater Res A 2014; 102:611-620.

58 Bugmann P, Rimensberger PC, Kalangos A, Barazzone C, Beghetti M, Lang FJ: Extratracheal biodegradable splint to treat life-threatening tracheomalacia. Ann Thorac Surg 2004; 78:1446-1448.

59 Zopf DA, Hollister SJ, Nelson ME, Ohye RG, Green GE: Bioresorbable airway splint created with a three-dimensional printer. N Engl J Med 2013;368:2043-2045.

60 Lochbihler H, Hoelzl J, Dietz HG: Tissue compatibility and biodegradation of new absorbable stents for tracheal stabilization: an experimental study. J Pediatr Surg 1997;32: 717-720

61 Korpela A, Aarnio P, Sariola H, Törmälä P, Harjula A: Bioabsorbable self-reinforced poly-L-lactide, metallic, and silicone stents in the management of experimental tracheal stenosis. Chest 1999;115:490-495.

62 Korpela A, Aarnio P, Sariola H, Törmälä P, Harjula A: Comparison of tissue reactions in the tracheal mucosa surrounding a bioabsorbable and silicone airway stents. Ann Thorac Surg 1998;66:1772-1776. 
63 Robey TC, Välimaa T, Murphy HS, Tôrmâlâ P, Mooney DJ, Weatherly RA: Use of internal bioabsorbable PLGA 'finger-type' stents in a rabbit tracheal reconstruction model. Arch Otolaryngol Head Neck Surg 2000;126:985991.

64 Saito Y, Minami K, Kobayashi M, Nakao Y, Omiya H, Imamura H, Sakaida N, Okamura A: New tubular bioabsorbable knitted air way stent: biocompatibility and mechanical strength. J Thorac Cardiovasc Surg 2002;123: 161-167.

-65 Saito Y, Minami K, Kaneda H, Okada T, Maniwa T, Araki Y, Imamura $H$, Yamada $H$, Igaki K, Tamai H: New tubular bioabsorbable knitted airway stent: feasibility assessment for delivery and deployment in a dog model. Ann Thorac Surg 2004;78:1438-1440.
66 Liu KS, Liu YH, Peng YJ, Liu SJ: Experimental absorbable stent permits airway remodeling. J Thorac Cardiovasc Surg 2011;141:463-468.

67 Novotny L, Crha M, Rauser P, Hep A, Misik J, Necas A, Vondrys D: Novel biodegradable polydioxanone stents in a rabbit airway model. J Thorac Cardiovasc Surg 2012;143:437444.

68 Lischke R, Pozniak J, Vondrys D, Elliott MJ: Novel biodegradable stents in the treatment of bronchial stenosis after lung transplantation. Eur J Cardiothorac Surg 2011;40:619624.

69 Vondrys D, Elliott MJ, McLaren CA, Noctor C, Roebuck DJ: First experience with biodegradable airway stents in children. Ann Thorac Surg 2011;92:1870-1874.
70 Serio P, Fainardi V, Leone R, Baggi R, Grisotto L, Biggeri A, Mirabile L: Tracheobronchial obstruction: follow-up study of 100 children treated with airway stenting. Eur J Cardiothorac Surg 2014;45:e100-e109.

71 Antón-Pacheco JL, Comas JV, Luna C, Benavent MI, López M, Ramos V, Méndez MD: Treatment strategies in the management of severe complications following slide tracheoplasty in children. Eur J Cardiothorac Surg 2014;46:280-285.

72 Wang J, Boutin KG, Abdulhadi O, Personnat LD, Shazly T, Langer R, Channick CL, Borenstein JT: Fully biodegradable airway stents using amino alcohol-based poly(ester amide) elastomers. Adv Healthc Mater 2013;2:13291336. 